\title{
TUBERCULOSIS IN B.C.G. VACCINATED CHILDREN IN SINGAPORE
}

\author{
BY \\ FREDA M. PAUL \\ From the Paediatric Unit, the General Hospital, Singapore
}

(RECEIVED FOR PUBLICATION JANUARY 11, 1961)

B.C.G. vaccination is generally considered a useful adjunct in the fight against tuberculosis. Although it does not necessarily completely protect the subject from contracting tuberculosis, it probably prevents the more severe forms of the disease such as tuberculous meningitis, miliary tuberculosis and the severe pulmonary forms of the disease. To assess the real value of B.C.G. vaccination, it is necessary to isolate the subject from contacts, until the conversion of the Mantoux tuberculin test proves effective vaccination. That B.C.G. vaccination is not completely protective against the development of tuberculous meningitis has been proved by Lorber and Menneer (1959), but that it does have considerable protective effect on the development of tuberculosis has been shown by the recent trials carried out by the Medical Research Council (1959) where the incidence of tuberculosis in the B.C.G. vaccinated group was 0.38 per 1,000 compared with $2 \cdot 29$ per 1,000 among those in the tuberculin negative unvaccinated group who were admitted concurrently. This represents a reduction attributable to vaccination of $83 \%$.

Field trials of B.C.G. have so often been open to criticism for one reason or another, but what we wanted to find out was the effect of mass campaigns where isolation of the patient was not practical.

In Singapore, the U.N.I.C.E.F./W.H.O. team initiated B.C.G. vaccination in June 1951. Up to the end of 1953, a total of 35,894 people were inoculated, of whom only 1,607 were newborn. In 1957, a mass B.C.G. campaign amongst the newborn was started at the main Kandang Kerbau Maternity
Hospital. Almost $50 \%$ of the babies born on the island are delivered at this Hospital.

Table 1 shows the number of cases vaccinated each year with the total number of births from Singapore.

The number of cases of tuberculous meningitis admitted to the Paediatric Unit, General Hospital, is shown in Table 2 .

TABLE 2

NUMBER OF CASES OF TUBERCULOUS MENINGITIS ADMITTED IN PAEDIATRIC UNIT, GENERAL HOSPITAL, SINGAPORE

\begin{tabular}{c|c|c|c}
\hline Year & No. of Cases & $\begin{array}{c}\text { Mortality } \\
(\%)\end{array}$ & $\begin{array}{c}\text { Total Number } \\
\text { of Admissions }\end{array}$ \\
\hline 1955 & 112 & $60 \cdot 7$ & No. not available \\
6,473 \\
1956 & 106 & $44 \cdot 3$ & 7,217 \\
1957 & 60 & $45 \cdot 7$ & 9,697 \\
1958 & 52 & $30 \cdot 7$ & 10,517 \\
1959 & 45 & $28 \cdot 9$ & \\
$\begin{array}{c}1960 \\
\text { (from Jan. } \\
\text { to Sept.) }\end{array}$ & 36 & $16 \cdot 6$ & 8,400 \\
\hline
\end{tabular}

The Paediatric Unit admits children up to 10 years of age, and about $90 \%$ of children requiring medical treatment are admitted here. The figures, therefore, give a good idea of the pattern of disease in children on the island. It will be seen that the incidence of tuberculous meningitis dropped considerably in 1957. Factors which helped to bring this about were better adult control of tuberculosis, a mass x-ray campaign and the introduction of B.C.G. vaccination.

Of particular interest, however, were 14 cases of

TABLE 1

\begin{tabular}{|c|c|c|c|c|c|c|c|c|c|c|}
\hline & & & & & & 1956 & 1957 & 1958 & 1959 & $\begin{array}{c}1960 \\
\text { (Jan. to June) }\end{array}$ \\
\hline \multicolumn{5}{|c|}{$\begin{array}{l}\text { Number of B.C.G. vaccinations at Kandang Kerbau Hospital } \\
\text { Number of B.C.G. vaccinations at Infant Welfare Clinic: }\end{array}$} & $\cdots$ & - & 22,168 & & & 15,072 \\
\hline (a) Urban (commenced July 1958) & . & .. & .. & . & $\cdots$ & - & & 2,904 & 5,936 & 2,815 \\
\hline (b) Rural (commenced July 1956) & .. & . & . & . & $\cdots$ & 221 & $\begin{array}{r}517 \\
605\end{array}$ & 2,866 & 4,078 & 2,597 \\
\hline Number of births in Singapore ... & - & .. & $\cdots$ & $\cdots$ & $\cdots$ & & 62,685 & 63,572 & 62,464 & 29,844 \\
\hline
\end{tabular}


TABLE 3

AGE, INCIDENCE AND SEX DISTRIBUTION OF 14 CASES OF TUBERCULOUS MENINGITIS

\begin{tabular}{|c|c|c|c|c|}
\hline $\begin{array}{l}\text { Case } \\
\text { No. }\end{array}$ & $\begin{array}{c}\text { Age } \\
\text { yrs mths }\end{array}$ & Sex & $\begin{array}{l}\text { Mantoux Tests } \\
\text { Old Tubercu }\end{array}$ & $\begin{array}{l}\text { s with } \\
\text { ulin }\end{array}$ \\
\hline $\begin{array}{r}1 \\
2 \\
3 \\
4 \\
5 \\
6 \\
7 \\
8 \\
9 \\
9 \\
10 \\
11 \\
12 \\
13 \\
14\end{array}$ & $\begin{array}{rr}1 & \\
2 & \\
1 & 4 \\
2 & \\
2 & \\
1 & 4 \\
2 & 7 \\
2 & 7 \\
& 10 \\
1 & \\
2 & \\
2 & \end{array}$ & $\begin{array}{l}\text { Male } \\
\text { Female } \\
\text { Female } \\
\text { Female } \\
\text { Female } \\
\text { Female } \\
\text { Female } \\
\text { Female } \\
\text { Male } \\
\text { Male } \\
\text { Male } \\
\text { Male } \\
\text { Male } \\
\text { Female }\end{array}$ & $\begin{array}{l}1 / 1,000 \text { dilution } \\
1 / 100 \\
1 / 1,000 \quad \text { ", } \\
1 / 1,000 \quad \text { ", } \\
1 / 1,000 \quad \text { ", } \\
1 / 1,000 \quad \text { ", } \\
1 / 100 \\
1 / 100 \\
1 / 1,000 \text { and } 1 / 100 \\
1 / 1,000 \text { dilion } \\
1 / 1000 \text { dilution } \\
1 / 1,000 \quad \text { ", } \\
1 / 100 \\
1 / 100 \quad \text { ", }\end{array}$ & $\begin{array}{l}\text { positive } \\
\text { positive } \\
\text { positive } \\
\text { positive } \\
\text { positive } \\
\text { positive } \\
\text { positive } \\
\text { positive } \\
\text { positive } \\
\text { negative } \\
\text { positive } \\
\text { positive } \\
\text { negative } \\
\text { negative }\end{array}$ \\
\hline
\end{tabular}

tuberculous meningitis (Table 3) and two cases of severe pulmonary tuberculosis in children, who had received B.C.G. vaccination at birth, and had been admitted to the Paediatric Unit, the General Hospital, during the years 1958, 1959 and 1960.

It will be noted that six of these children were in the 2-year age period, four were 1 year old, and four under the age of 1 year. The youngest case was 7 months old. The concentration of the disease under the age of 2 years shows the poor resistance of these children in this young age group in spite of immunization.

There was no striking difference in the sex incidence.

\section{Investigations}

B.C.G. In all these cases B.C.G. had been given at birth at the Kandang Kerbau Maternity Unit. The presence of a scar was noted in all cases by the examining doctor. In three children Mantoux testing was done three months after the vaccination by the B.C.G. team and all three were reported to be positive.

It is not known whether the rest of the children had been tuberculin converted, but from an original survey in 1957 it is known that $97 \%$ of B.C.G. vaccinated newborn infants in Singapore had a Mantoux conversion at 3 months of age.

Mantoux Tests. Thirteen of the 14 cases had a positive Mantoux test when tested in the wards after admission (seven were positive to 1 in 1,000 old tuberculin and five to 1 in 100 old tuberculin). Case 10 had a negative Mantoux test in the ward, but was reported to have had a positive Mantoux test three months after the B.C.G. vaccination at birth. This child developed internal hydrocephalus and eventually died. It is well known that in a severe form of the disease the Mantoux test will be negative, and this probably accounts for the negative reaction.

The striking feature of this group of cases of tuberculous meningitis occurring in children who had received B.C.G. at birth in contrast to those who had no B.C.G. was the very short history, and the quick recovery and return of the cerebrospinal fluid to normal: The short history of these cases made it difficult to distinguish them from Japanese B encephalitis that occurs so commonly here. Table 4 shows the average length of history in each case and the main symptoms.

It will be noted that 12 of the 14 cases gave a history of symptoms lasting 10 days or less than 10 days.

Fever was present in all cases, fits in $64 \%$, vomiting in $57 \%$, drowsiness in $86 \%$, constipation in $36 \%$ and paralysis in $14 \%$ of the cases. These were the symptoms described by the parents on admission of the children.

TABLE 4

LENGTH OF HISTORY AND MAIN SYMPTOMS

\begin{tabular}{|c|c|c|c|c|c|c|c|}
\hline \multirow{2}{*}{$\begin{array}{l}\text { Case } \\
\text { No. }\end{array}$} & \multirow{2}{*}{$\begin{array}{l}\text { Average Length of } \\
\text { History }\end{array}$} & \multicolumn{6}{|c|}{ Symptoms } \\
\hline & & Fever & Fits & Vomiting & Drowsiness & Paralysis & Constipation \\
\hline $\begin{array}{r}1 \\
2 \\
3 \\
4 \\
5 \\
6 \\
7 \\
8 \\
9 \\
10 \\
11 \\
12 \\
13 \\
14\end{array}$ & $\begin{array}{r}3 \text { weeks } \\
1 \text { week } \\
3 \text { days } \\
10 \text { days } \\
10 \text { days } \\
2 \text { days } \\
1 \text { week } \\
1 \text { week } \\
1 \text { month } \\
4 \text { days } \\
3 \text { days } \\
5 \text { days } \\
7 \text { days } \\
2 \text { days }\end{array}$ & $\begin{array}{l}+ \\
+ \\
+ \\
+ \\
+ \\
+ \\
+ \\
+ \\
+ \\
+ \\
+ \\
+ \\
+\end{array}$ & $\begin{array}{l}\frac{+}{+} \\
\frac{+}{+} \\
+ \\
+ \\
+ \\
+ \\
+ \\
+ \\
+\end{array}$ & $\begin{array}{l}\overline{+} \\
+ \\
+ \\
+ \\
+ \\
+ \\
+ \\
+ \\
\frac{+}{+}\end{array}$ & $\begin{array}{l}+ \\
+ \\
+ \\
+ \\
+ \\
+ \\
+ \\
+ \\
+ \\
+ \\
+ \\
+ \\
+\end{array}$ & $\begin{array}{l}\bar{z} \\
+ \\
\overline{+} \\
\bar{z} \\
\bar{z} \\
\bar{z} \\
\bar{z} \\
\overline{-}\end{array}$ & $\begin{array}{l} \pm \\
\overline{-} \\
+ \\
\pm \\
\pm \\
\pm \\
\pm \\
- \\
- \\
-\end{array}$ \\
\hline
\end{tabular}

+ Present; - Absent. 
TABLE 5

SIGNS PRESENT AT INITIAL EXAMINATION

\begin{tabular}{|c|c|c|c|c|c|c|c|}
\hline $\begin{array}{l}\text { Case } \\
\text { No. }\end{array}$ & Coma & $\begin{array}{l}\text { Rigidity } \\
\text { of Limbs }\end{array}$ & $\begin{array}{c}\text { Neck } \\
\text { Rigidity }\end{array}$ & $\begin{array}{c}\text { Paralysis } \\
\text { Limbs }\end{array}$ & $\begin{array}{c}\text { Facial } \\
\text { Paralysis }\end{array}$ & Papilloedema & $\begin{array}{l}\text { Abnormal } \\
\text { Movement }\end{array}$ \\
\hline $\begin{array}{r}1 \\
2 \\
3 \\
4 \\
5 \\
6 \\
7 \\
8 \\
9 \\
10 \\
11 \\
12 \\
13 \\
14\end{array}$ & $\begin{array}{r}+ \\
+ \\
+ \\
+ \\
+ \\
+ \\
+ \\
++ \\
+ \\
++ \\
+ \\
+ \\
+ \\
+\end{array}$ & $\begin{array}{l}+ \\
+ \\
+ \\
+ \\
+ \\
+ \\
+ \\
+ \\
+ \\
+ \\
+\end{array}$ & $\begin{array}{l} \pm \\
\pm \\
\overline{+} \\
+ \\
\overline{-} \\
+ \\
+ \\
+ \\
+ \\
+\end{array}$ & $\begin{array}{l}\overline{+} \\
+ \\
+ \\
+ \\
\overline{+} \\
\overline{-} \\
\overline{-} \\
\overline{+} \\
+\end{array}$ & $\begin{array}{l}\bar{z} \\
\pm \\
\bar{z} \\
\overline{-} \\
\bar{z} \\
\bar{z} \\
\bar{z} \\
=\end{array}$ & $\begin{array}{l}\bar{z} \\
\bar{z} \\
\bar{z} \\
\bar{z} \\
\bar{t} \\
\bar{z} \\
\bar{z} \\
\overline{-}\end{array}$ & $\begin{array}{l}\overline{ \pm} \\
\overline{-} \\
\overline{-} \\
\pm \\
\pm \\
\bar{z} \\
\overline{-} \\
\overline{-}\end{array}$ \\
\hline
\end{tabular}

+ Present; $\quad++$ Moderate; $\quad+++$ Deep; - Absent

Case 4 was admitted with left hemiparesis and fever and did not look too ill at the onset of admission. The parents refused medical treatment and took the child home against medical advice on the day of admission. He was readmitted in coma four days later and died the next day. Autopsy showed miliary tuberculosis with tuberculosis of the meninges.

Case 14 is interesting because of the close resemblance to a case of febrile fits. He had a normal cerebrospinal fluid on admission, but was readmitted two days later in coma with cerebrospinal fluid changes. He eventually responded to anti-tuberculous treatment.

The temperature returned to normal by the end of the second week and improvement clinically and serologically became evident by the end of the second week.

Physical Signs. As the cerebrospinal fluid of these cases on direct smear and on culture did not show the tubercle bacillus, the clinical picture of the child, together with the radiological findings and the biochemical findings of the cerebrospinal fluid were vitally important.

Table 5 illustrates the main signs present in each case on initial examination.

All the children were in varying degrees of coma. The vacant stare so characteristic of tuberculous meningitis was present in most of the cases. Rigidity of the limbs was present in $71 \%$, while flaccidity of the limbs in the form of hemiparesis was present in $36 \%$ of cases. Two children had papilloedema, one due to the development of internal hydrocephalus. This child came in with a four-day history of fever and fits. The cerebrospinal fluid showed a total protein of $200 \mathrm{mg}$. \% on admission. The child was comatose throughout the four months' stay in hospital. In spite of intrathecal prednisolone the child did not respond. Fig. 1 shows the air encephalogram indicating the dilated lateral ventricles.
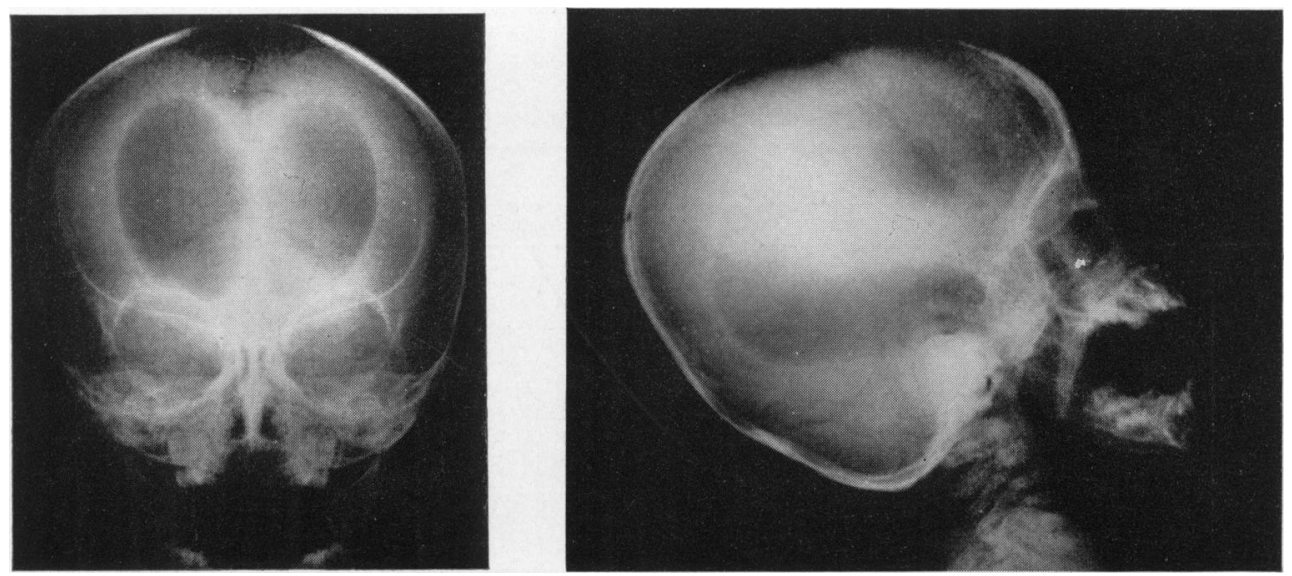

FIG. 1.-Air encephalogram indicating the dilated lateral ventricles. 
TABLE 6

THE CEREBROSPINAL FLUID CHANGES

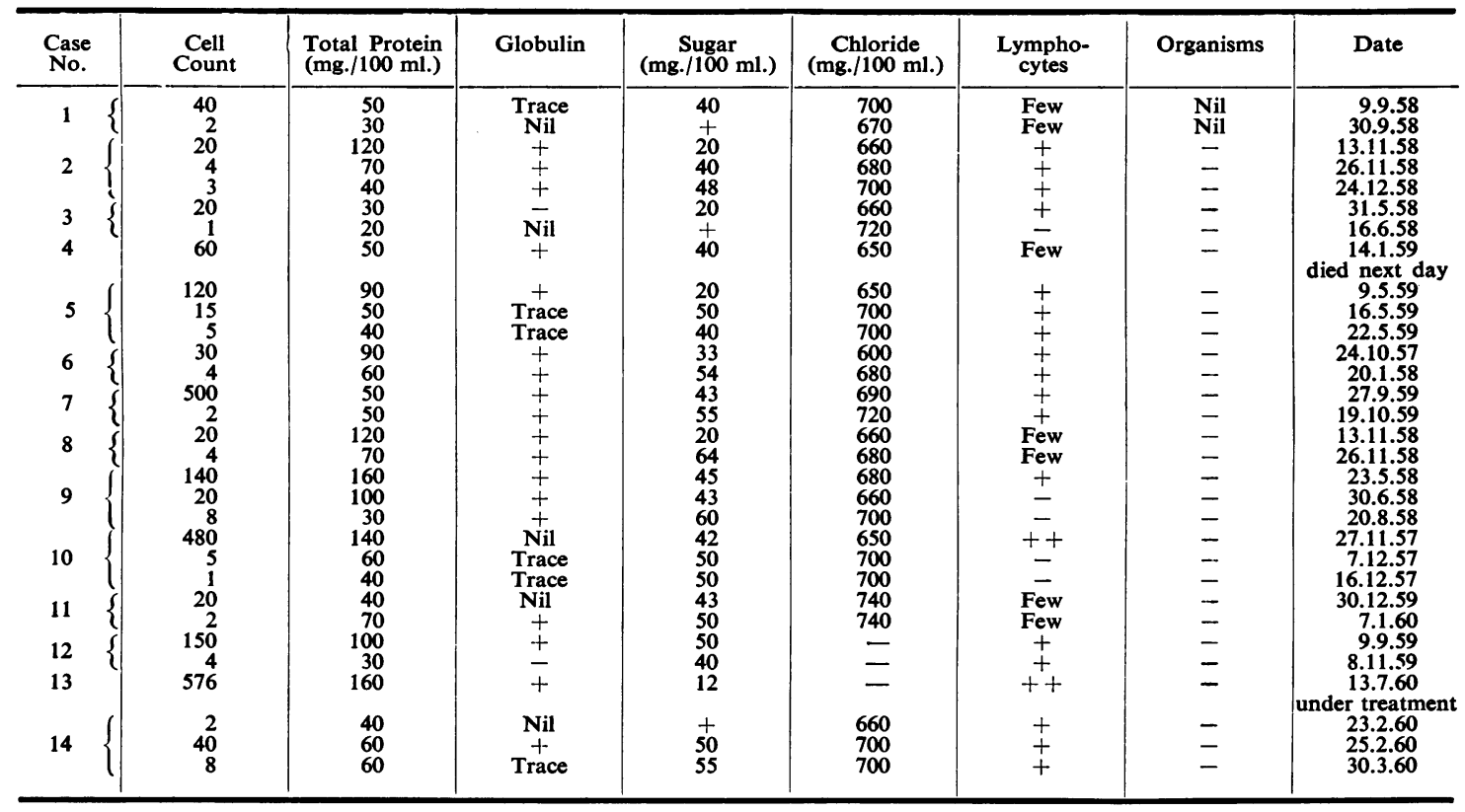

Radiological Evidence. Radiologically there was evidence of a primary infection in all except one case. In nine cases there were increased hilar markings with evidence of calcification on later radiographs, while two cases had widening of the superior mediastinum and two others had consolidation of the right middle lobe. Case 1 had miliary tuberculosis of the lungs.

Deaths. There were three deaths among the 14 children. Case 3 was a 2-year-old Sikh child who was treated as a case of tuberculous meningitis, recovered and was discharged. She was followed as an out-patient and three months later was admitted with severe hyperpyrexia and fits after an attack of tonsillitis; she died.

The parents of Case 4 refused to admit the child to hospital. She was admitted in coma four days later and eventually died. Autopsy showed an indurated mass at the apical portion of the right lower lobe with miliary tubercles scattered throughout both lungs. The right tracheobronchial lymph nodes were enlarged and matted. The liver and spleen were studded with tubercles and the base of the brain had a fibrinous exudate with miliary tubercles. Case 10 was admitted in a comatose state and did not improve in spite of treatment. She developed an internal hydrocephalus and died six months after admission. There was no autopsy.

Cerebrospinal Fluid Changes. The mean of the first specimens of the cerebrospinal fluid taken within 12 hours of admission were, cells: 20-500/ c.mm. (mean: 40/c.mm.); total protein: 50-160 mg. $/ 100 \mathrm{ml}$. (mean: $100 \mathrm{mg} . / 100 \mathrm{ml}$.); glucose: $12-50 \mathrm{mg} . / 100 \mathrm{ml}$. (mean: $40 \mathrm{mg} . / 100 \mathrm{ml}$.).

The cells were predominantly lymphocytes. The cerebrospinal fluid in tuberculous meningitis in the non-vaccinated group normally takes one to three months to return to normal. In some cases where the protein is high this may take six months. It was observed that in the B.C.G. vaccinated group the cerebrospinal fluid returned to normal much sooner.

Table 6 shows the initial cerebrospinal fluid changes and the time taken to return to normal.

Contacts. With the aid of the almoner and by interview with the parents it was found that six of the children had been in contact with adults suffering from pulmonary tuberculosis. Case $3 \mathrm{had}$ been in contact with a Chinese neighbour suffering from pulmonary tuberculosis. The father of Case 5 had pulmonary tuberculosis. Case 6 had a tuberculous mother who was under treatment 


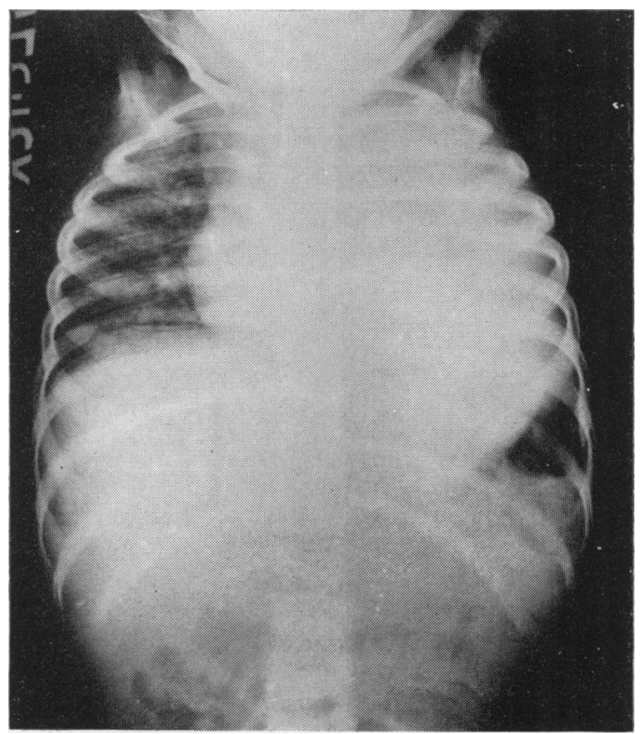

FIG. 2.-Radiograph showing left pleural effusion and miliary mottlings of the right lung.

for tuberculosis. The almoner's report on Case 9 stated that 25 to 30 people were living in the same house with the patient. Out of these, two were known to have pulmonary tuberculosis. One occupant had recently died of pulmonary tuberculosis, while the second occupant was the patient's aunt who attended the tuberculous hospital for

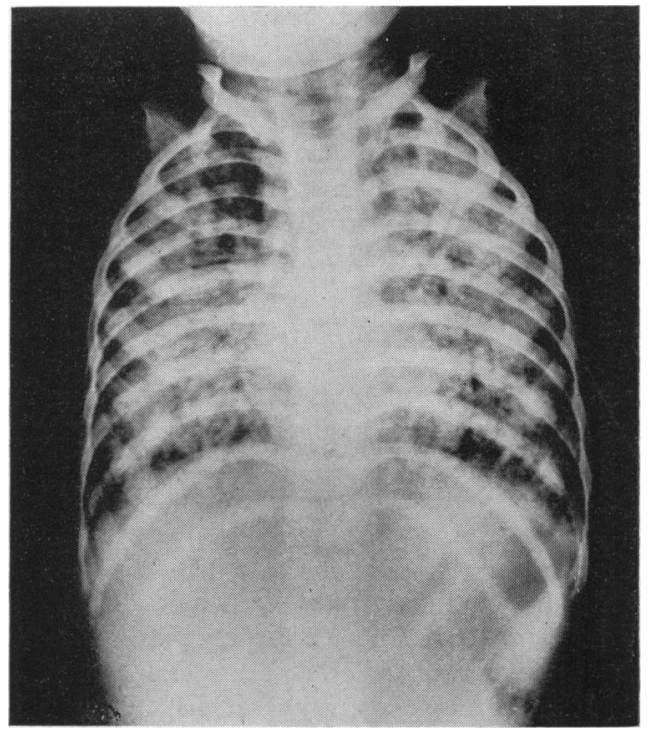

FIG. 3.-Radiograph showing tuberculous bronchopneumonia. treatment. This case was the youngest child in this series, aged 7 months, who had been given B.C.G. at birth and was known to be tuberculin positive three months later. Overcrowding and inadequate facilities for isolation of children from contact with tuberculous parents and relatives are a problem here.

Sequelae. These children have not been followed up long enough to estimate their mental state. Physically, three had hemiparesis and one developed internal hydrocephalus. Case 7 is mentally backward. Three children were reported by the parents to be extremely mischievous and to have temper tantrums.

\section{Case Reports}

The following two cases are interesting in that they represent two fulminating types of pulmonary tuberculosis developing in children in spite of having been B.C.G. vaccinated at birth.

Case 1. A Malay child, aged 4 years, was admitted to the Paediatric Unit because of low-grade evening fever for five months, cough for three months, and loss of weight over a period of five months. She was the second child in a family of three and was given B.C.G. at birth.

On clinical examination the child was emaciated with a temperature of $101^{\circ} \mathrm{F}$., and breathless with poor movement of the left side of the chest. A pleural effusion was suspected clinically because the percussion note was dull and the air entry was poor. The liver was enlarged, being palpable one finger breadth below the costal margin. The right fundus showed choroidal tubercles. Radiologically there was a left pleural effusion with miliary mottling of the right lung (Fig. 2.)

Mantoux test to old tuberculin in the dilution of $1 / 1,000$ and $1 / 100$ was negative. The sputum, however, showed acid-fast bacilli on direct smear. A lumbar puncture was done to exclude tuberculous meningitis, but the cerebrospinal fluid was found to be normal serologically. In this case the contact was an aunt who was living in the same house and who had pulmonary tuberculosis for which she was under treatment. After a week's stay in hospital the parents took the child home, against medical advice, and she is now attending an out-patient clinic for streptomycin injections.

Case 2. A 15-month-old Chinese child was admitted in August 1960, with a three-month history of low-grade fever, associated with cough. He was a normal baby at birth, given B.C.G. at the Kandang Kerbau Maternity Hospital and had developed normally till three months before admission.

On examination he was ill, emaciated, extremely pale and breathless. On clinical examination there was consolidation of the left upper lobe with coarse râles over both lungs. The abdomen was scaphoid with a liver two finger breadths below the costal margin, and 


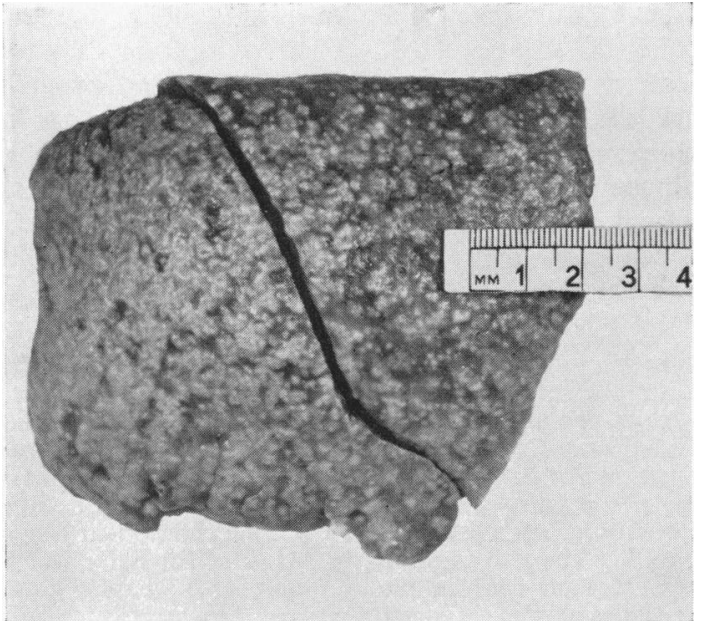

FIG. 4.-Autopsy specimen of the lungs. Note that the left lung is riddled with patchy coarse areas of tuberculosis.

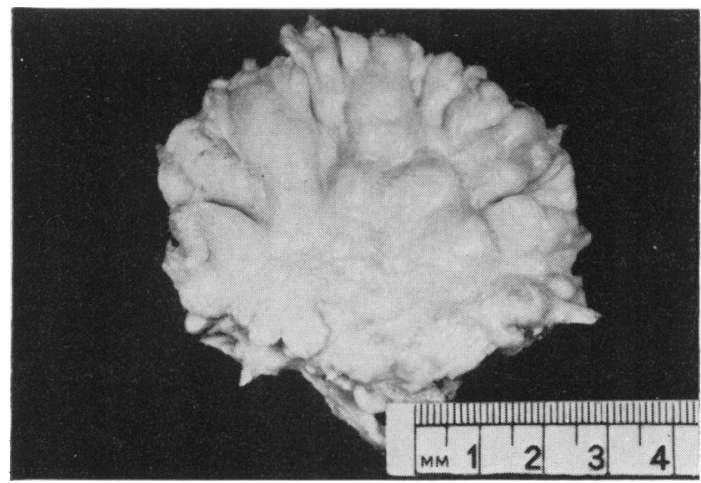

FIG. 6.-Autopsy specimen of the enlarged mesenteric glands.

enlarged mesenteric glands were palpable. There were no neurological signs. The cerebrospinal fluid was normal, the B.S.R. was only $6 \mathrm{~mm}$. and the Mantoux test was negative. Radiologically there was coarse mottling of both lungs, consistent with tuberculous bronchopneumonia (Fig. 3).

In this case the contact was an uncle, who was being followed up at the T.B. Hospital for pulmonary tuberculosis, and lived in the same room as the rest of the patient's family, which included seven other children.

This child died three days after admission. Autopsy revealed bronchogenic tuberculosis with enlarged cervical and mesenteric lymph nodes (Figs. 4-7).

\section{Discussion}

It has been demonstrated many times that B.C.G. vaccination can prevent tuberculosis. For example, Aronson, Aronson and Taylor (1958)

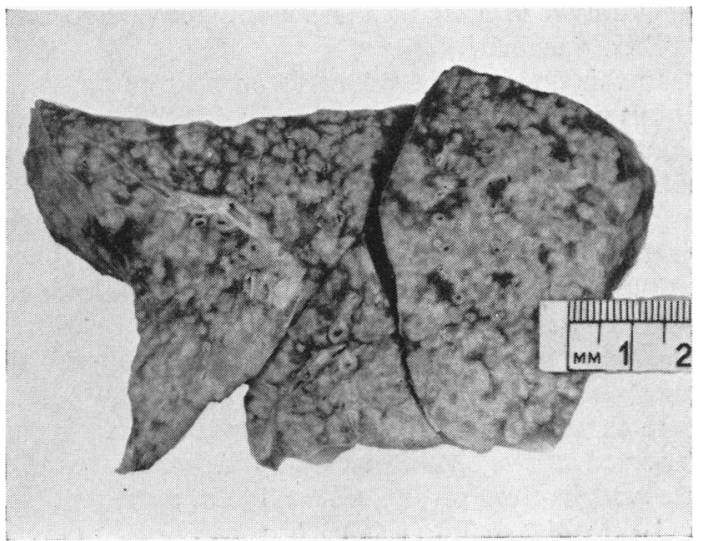

Fig. 5.-The left lung with the bronchus of the left lower lobe infiltrated with tuberculous granulation tissue.

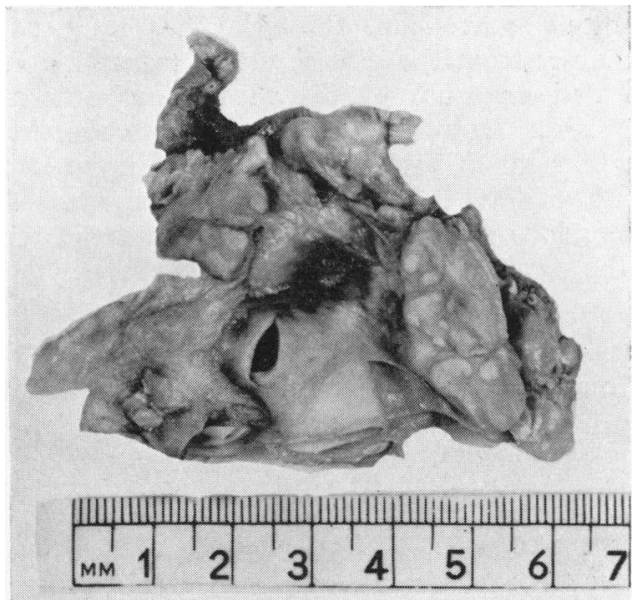

Fig. 7.-Cross-section of the enlarged lymph nodes showing caseation.

vaccinated 1,557 American Indian children 20 years ago and left 1,457 as controls. The incidence of tuberculosis in that community was high at the time these vaccinations were done. Twenty years later they found that $6.7 \%$ of the vaccinated group had died, tuberculosis being responsible for $0.8 \%$ of the deaths. Of the controls $10.4 \%$ died, tuberculosis accounting for $4.7 \%$ of cases. Hyge (1947) observed an epidemic of tuberculosis in a school in Denmark. Of 94 tuberculin negative children who were exposed to an infectious school teacher, 41 developed tuberculosis; whereas of the 106 B.C.G. vaccinated children who were exposed to the same infection, only two developed the disease.

Lorber and Menneer (1959) reported a case of a 4-month-old infant who contracted tuberculosis when contact was resumed with her tuberculous 
grandfather in spite of a successful conversion after B.C.G. vaccination.

In this country there have been no reports so far about the long-term effectiveness of B.C.G. vaccination in contacts. The incidence of childhood tuberculosis has dropped in this country and the introduction of B.C.G. has no doubt played a great part in the reduction. But the 14 cases of tuberculous meningitis and two cases of pulmonary tuberculosis in B.C.G. vaccinated children reported above are interesting in that they show that B.C.G. does not provide complete immunity.

In three of the 14 cases of tuberculous meningitis reported above, Mantoux tests three months after the vaccination of B.C.G. at birth were reported to be positive. Two of the three cases had relatives with tuberculosis living in the same room or house. This further proves the point that even after Mantoux conversion, the child has no absolute immunity from the disease unless protection from repeated exposure to the tuberculous subject is exercised. However, it is interesting to observe the short length of history of symptoms given in this group of B.C.G. vaccinated children developing tuberculous meningitis and the rather rapid return of the cerebrospinal fluid to normal.

\section{Summary}

Fourteen cases of tuberculous meningitis and two cases of pulmonary tuberculosis in B.C.G. vaccinated children are reported. Their symptoms, clinical features, cerebrospinal fluid changes, and progress are discussed. Considering the large number of children who are being vaccinated with B.C.G. in Singapore and the small number that develop tuberculosis, it can be concluded that B.C.G. vaccination during the neonatal period provides considerable if not absolute immunity.

I wish to thank Dr. C. E. Field, head of the Paediatric Unit, General Hospital, Singapore, for her advice, encouragement and help in this paper; Dr. Quah Quee Guan and Dr. Wong Hock Boon for permission to make use of patients in their unit; Dr. Ho Kok Kheong for the autopsy reports, and to Dr. Wong Hin Sung for supplying statistics on B.C.G. vaccination in Singapore. I am also indebted to Mr. Ho Tat Seng and to Mr. Naplon for the photographs. My thanks go to the Director of Medical Services, Singapore, for permission to publish this paper.

\section{REFERENCES}

“Annual report of the Medical Department, 1952." Colony O Singapore (1953). p. 116. Government Printing Office,

Singapore.
Aronson, J. D., Aronson, C. F. and Taylor, H. C. (1958). A twentyyear appraisal of B.C.G. vaccination in the control of tuberculosis. A.M.A. Arch. intern. Med., 101, 881.

Hyge, T. V. (1947). Epidemic of tuberculosis in state school, with observation period of about 3 years. Acta tuberc. scand., 21, 1.

Lorber, J. and Menneer, P. C. (1959). Long-term effectiveness of B.C.G. vaccination of infants in close contact with infectious tuberculosis. Brit. med. J., 1, 1430.

Medical Research Council (1959). B.C.G. and vole bacillus vaccines in the prevention of tuberculosis in adolescents. Ibid., 2, 379 . 